\title{
Aplicación y límites de la inmunidad diplomática, a la luz de las normas del "ius cogens"*
}

\author{
Recibido: 13 de agosto de 2018 • Aprobado: 23 de julio de 2019 \\ https://doi.org/10.22395/ojum.v19n38a13 \\ Maicol Andrés Rodríguez Bolañoz* \\ Sebastian Portilla Parra***
}

\section{RESUMEN}

La inmunidad diplomática, en sus diferentes modalidades, procura el eficiente desarrollo de la actividad y objetivo del cuerpo diplomático. Integra, así, una amplia gama de prerrogativas y exenciones, debido a la soberanía e igualdad entre los Estados. Empero, posee límites que no se han desarrollado y aplicado de manera uniforme a nivel nacional e internacional, pues aún no existe consenso sobre si esta institución debe aplicarse conforme a su dimensión iure imperii o iure gestionis. En este contexto, el presente artículo de reflexión procura brindar luces respecto a esta controversia, que perjudica la comprensión, estudio y aplicación de esta figura. Lo anterior toma mayor complejidad al momento de atender las normas del ius cogens y el derecho internacional de los derechos humanos, esto es, cuando se vulneran estas normas bajo el amparo de la inmunidad diplomática, aunque las cortes internacionales y la doctrina no están contentos en una interpretación respecto de los límites y alcances de dicha inmunidad. Para finalizar, se presenta el caso colombiano y se enfatizan las ambigüedades de la jurisprudencia de las altas cortes que manejan tesis divergentes. En este sentido, los derechos fundamentales dependen de la jurisdicción a la cual acudan, lo que genera inseguridad jurídica, en contravía de lo profesado desde nuestra norma superior.

Palabras clave: aplicación; acceso a la justicia; derechos humanos; inmunidad diplomática; límites; normas del ius cogens.

El presente artículo se deriva de la actividad investigativa al interior del Semillero de Investigación Observatorio de Bioética, Bioderecho y Derechos Humanos y del caso litigioso desarrollado en Azur \& Cía. S.A.S.

** Abogado, magister en Derecho Médico. Investigador externo, Grupo de Investigación Derecho Médico, Derechos Humanos y Bioética, Universidad del Cauca, Popayán, Colombia. Abogado litigante, Azur E Cía. S.A.S., Popayán, Colombia. Correo electrónico: maicolrodriguez@azurabogados.com.

*** Abogado, estudiante extranjero, Universidad Carlos III de Madrid. Miembro del Grupo de Investigación Derecho Médico, Derechos Humanos y Bioética y del Semillero de Investigación Observatorio de Bioética, Bioderecho y Derechos Humanos, Universidad del Cauca, Popayán, Colombia. Correo electrónico: sebastianparraportilla@gmail.com. 


\title{
Enforcement and Limits of Diplomatic Immunity in the Light of the "lus Cogens" Norms
}

\begin{abstract}
Diplomatic immunity, on its different modalities, procures the efficient development of the activities and objectives of a diplomatic corps. It integrates, thus, a wide variety of prerogatives and exemptions due to sovereignty and equality among States. Nonetheless, it has limits that have not been developed or applied uniformly nationally and internationally given that there is no consensus about whether must be applied in conformity to its iure imperii or iure gestionis dimension. In this context, this reflection article aims towards shedding light on this controversy that harms the comprehension, study, and application of this figure. The former takes greater complexity when attending the ius cogens norms and international law of human rights, i.e. when these norms are infringed under the protection of diplomatic immunity, even though the international courts and the doctrine are not pleased in an interpretation regarding the limits and scope of said immunity. Summarizing, we present the Colombian case and emphasize in the ambiguities of the high courts' jurisprudence with a divergent thesis. Thus, the fundamental rights depend on the agreed jurisdiction, which generates judicial insecurity and against what's stated in our higher laws.
\end{abstract}

Keywords: application; access to justice; human rights; diplomatic immunity; limits; ius cogens norms.

\section{Aplicação e limites da imunidade diplomática, à luz das normas do jus cogens}

\section{RESUMO}

A imunidade diplomática, em suas diferentes modalidades, procura o eficiente desenvolvimento da atividade e do objetivo do corpo diplomático. Assim, integra várias prerrogativas e isenções, devido à soberania e à igualdade entre os Estados. Contudo, apresenta limites que não vêm sendo desenvolvidos e aplicados de maneira padronizada no âmbito nacional e internacional, pois ainda não existe consenso sobre se essa instituição deve ser aplicada conforme sua dimensão jure imperii ou jure gestionis. Nesse contexto, este artigo de reflexão pretende oferecer esclarecimentos a respeito dessa controvérsia, que prejudica a compreensão, estudo e aplicação dessa figura. Isso toma maior complexidade no momento de atender às normas jure gestionis e o direito internacional dos direitos humanos, isto é, quando essas normas são violadas sob o amparo da imunidade diplomática, embora as cortes internacionais e a doutrina não estejam satisfeitas em uma interpretação quanto aos limites e alcances dessa imunidade. Por último, é apresentado o caso colombiano e enfatizadas as ambiguidades da jurisprudência das altas cortes que trabalham com teses divergentes. Nesse sentido, os direitos fundamentais dependem da jurisdição à qual recorram, o que gera insegurança jurídica, em contramão do professado a partir de nossa norma superior.

T3 Palavras-chave: aplicação; acesso à justiça; direitos humanos; imunidade diplomática; limites; normas do jus cogens. 


\section{INTRODUCCIÓN}

Según Napoleón I, la "diplomacia es el ejército en traje y adorno" (Balzac, 1999), mediante la cual los gobiernos manifiestan su poder y capacidad. Los Estados consideraban a sus diplomáticos como personas sagradas, receptoras de un sin número de beneficios y privilegios del cargo (Yang, 2013). Actualmente, la situación no es del todo diferente, aunque esta figura se desarrolle con base en la cortesía internacional recíproca, según el principio par in parem nom habet imperium o "nadie tiene potestad sobre su igual" (Yang, 2013) para fortalecer y mantener las buenas relaciones entre Estados.

Esta figura no se constituye en beneficio del individuo, sino con el fin de garantizar el desempeño eficaz de las funciones en cabeza de las misiones o el personal diplomático, como señalan las convenciones de Viena de 1964 y 1969. A primera vista, encontrar fundamentos suficientes para la existencia, respeto y prevalencia de la inmunidad diplomática no asume mayor complejidad, ya que también se presenta como consecuencia directa del principio internacional de igualdad soberana (Nuñez y Cifuentes, 2016) y el mantenimiento de las buenas relaciones y labores estatales.

Sin embargo, nacen controversias en relación con su aplicación. Por tanto, el texto estudia el caso de colisión entre normas del ius cogens (Dominicé, 1999) o del derecho internacional de los derechos humanos (DIDH) y la inmunidad diplomática. Esto quiere decir que cuando alguien infringe esta categoría normativa se encuentra amparado por la inmunidad diplomática, bien sea en su dimensión iure gestionis o bien iure imperii, ya que las consecuencias se alejan según el tipo de inmunidad aplicable al caso concreto. En estos aspectos se concentra parte de la discusión que convoca el presente artículo, para posteriormente determinar si prevalece la inmunidad diplomática o el respeto a las normas del ius cogens.

El objetivo general tiene que ver con la realización de un estudio integral y sistémico de lo que manifiesta la doctrina y la jurisprudencia internacional y nacional respecto a la aplicación de la inmunidad diplomática, según sea iure gestionis y/o iure imperii, en aras de lograr determinar las características propias de cada una. Además, se presentan los casos en donde se deben aplicar. Por último, se analiza si la inmunidad diplomática, aun en caso de transgredir normas del ius cogens, es prevalente o cede ante esta última.

Para encontrar los datos expuestos, el texto hace uso, en primera medida, de un análisis de las características y consecuencias de la inmunidad iure gestionis y/o iure imperio. En segundo lugar, se hace un estudio ponderado de las colisiones entre la aplicación de la inmunidad diplomática y las normas de ius cogens o del DIDH, con especial énfasis en el derecho de acceso a la administración de justicia en la doctrina internacional y jurisprudencia de la Corte Internacional de Justicia (CIJ) y el 
Tribunal Europeo de Derechos Humanos (TEDH). Finalmente, analiza la jurisprudencia nacional y su incidencia en nuestro ordenamiento jurídico, con sus incongruencias, deficiencias y avances.

El trabajo hace uso de una metodología cualitativa. Analiza el universo de investigación a través de un estudio de la doctrina y jurisprudencia relevante con respecto al problema de investigación para dilucidar el proceso de aplicación y limitación que ha tenido la inmunidad diplomática en la jurisprudencia y doctrina, para proponer un aporte cítrico desde la academia que responda a las necesidades actuales.

\section{LA INMUNIDAD DIPLOMÁTICA}

La inmunidad diplomática se refiere a los privilegios y beneficios otorgados a las personas contratadas por el Estado para realizar misiones diplomáticas o similares, y a quienes por vínculo familiar o contractual pueden asimilarse. Son otorgados por normas nacionales e internacionales: Convención de Viena de 1961, Convención sobre Misiones Especiales de New York de 1969, Convención de New York de 2004, tratados bilaterales o multilaterales, entre otros. La inmunidad diplomática evita la jurisdicción del país en el cual ejerce la misión diplomática (CDI, 1980), así como la ejecución del poder estatal en su perjuicio, y es efectiva desde que el agente diplomático entra en el territorio del Estado receptor por medio de acuerdo firmado con su consentimiento para ocupar el cargo.

El derecho internacional (en adelante DI) no se encuentra en estado puro, es interdisciplinario y recibe la influencia de diferentes factores, en especial de las relaciones internacionales entre Estados. Los intereses políticos que motivan el actuar de los Estados tienen consecuencias jurídicas internacionales en este campo (ZomosaSignoret, 2002) que se reflejan en el ordenamiento jurídico internacional y su andamiaje. Esto se materializa en el papel y preminencia que desde antaño ha ostentado la inmunidad diplomática en el derecho internacional.

Desde tiempos remotos, la inmunidad diplomática se ha aplicado de forma absoluta, lo que causa la pérdida total de poder jurisdiccional para el Estado receptor, pues no existía excepción prestablecida para la aplicación de la inmunidad diplomática, amparado en el principio de no intervención en los asuntos internos (Casella, 2013). Sin embargo, en virtud del carácter dinámico del DI público (Cabra, 2011), aunado a una interpretación evolutiva de sus normas (Lloret, 2017), desde la doctrina internacional se ha iniciado debate respecto a su aplicación con carácter restringido, configurando con ello excepciones para la aplicación de esta figura.

La aplicación restringida de la inmunidad diplomática significa la facultad estatal de limitar su jurisdicción en aplicación de la inmunidad diplomática con excepciones prestablecidas, en las cuales el agente diplomático se debería someter a 
condiciones idénticas que los particulares (Quintana Aranguren y Guzmán Carrasco, 2006). En este sentido, toma vital relevancia la Convención de las Naciones Unidas sobre las inmunidades jurisdiccionales de los estados y sus bienes en la Resolución 59/38 (2004). Sin embargo, un precitado debate solo se ha efectuado a nivel doctrinal, pues en reiterada jurisprudencia de tribunales como el CIJ y el TEDH, el debate es inexistente, dado que prevalece la idea de aplicar la inmunidad diplomática sin restricciones, o también la llamada iure imperii, en posición contrapuesta a tribunales penales internacionales que han aplicado la inmunidad diplomática iure gestionis.

Ahora bien, no puede negarse la importancia que ostenta la inmunidad diplomática en el ámbito internacional y diplomático entre los Estados, sin llegar a ser un aspecto de cortesía internacional (Corte Internacional de Justicia, 2012). Actualmente se considera una práctica consuetudinaria y de mantenimiento de las buenas relaciones estatales, aunque no representa un principio o regla general del derecho, ni tampoco puede ser óbice para el adecuado funcionamiento de la administración de justicia, o exceptuar competencia jurisdiccional sobre crímenes internacionales (Corte Institucional de Justicia, 2012, voto discidente magistrado Cançado Trindade).

\section{EL DI Y LA INMUNIDAD DIPLOMÁTICA EN SU APLICACIÓN}

La inmunidad diplomática, como hoy la conocemos, nació de un proceso consuetudinario iniciado en el siglo XIX de la práctica judicial de los Estados, con fundamento en la consideración de que los principios de soberanía, igualdad e independencia de los Estados no permiten el ejercicio de jurisdicción frente a Estados extranjeros (United States Supreme Court, 1812). En esta línea, la Organización de Naciones Unidas ha ostentado un rol preponderante en su regulación, especialmente en la Resolución 2625 (1970) de la Asamblea General, Convención sobre las inmunidades de los Estados y sus bienes. En esta se dan luces acerca de la manera de proceder en caso de controversias en el ejercicio de la inmunidad diplomática y se manifiesta que cada Estado tiene el deber de cumplir plenamente y de buena fe sus obligaciones internacionales y vivir en paz (Verdross, 1955).

De igual forma, no puede omitirse la importancia y prevalencia que tiene la Convención de Viena sobre Relaciones Diplomáticas (1961) o la Convención de New York (1969). En estas se concluye que los Estados deben respetar la inmunidad diplomática y otorgar determinados privilegios y exenciones frente al actuar de sus órganos judiciales a quienes la poseen.

Sin embargo, las normas que la regulan y del DI pueden colisionar. En este caso debe recordarse que si una persona comete un acto ilícito, el actuar como diplomático no le exime de responsabilidad, lo que genera tensión entre la inmunidad que le ampara y las normas de DI que tipifican el delito. 
De la misma manera, el Estado receptor debe proteger los derechos de todo individuo bajo su jurisdicción y no es competente para renunciar, inter se, a derechos que no son suyos, sino que son inherentes al ser humano. Por tanto, en caso de permitirse la inmunidad iure imperii (sin limitaciones), se opondría al orden público internacional y esta actuación deberá ser privada de todo efecto jurídico (Corte Internacional de Justicia, 2012). Ahora bien, en la práctica, tanto a nivel nacional como internacional, la generalidad es permitir esta inmunidad.

Así las cosas, se suscita la controversia relativa a la necesidad de desatender la inmunidad Iure imperii, pues contraviene inclusive la Convención de Viena, en la que su preámbulo señala que la inmunidad no es para las personas, sino para el eficaz desempeño de las funciones de las misiones diplomáticas. Este aspecto es cumplido por la inmunidad iure gestionis. Pero la inmunidad Iure imperii sobrepasa esta finalidad, ampara a la persona en sí, inclusive por ilícitos internacionales, irrespeto al ordenamiento jurídico del estado receptor, vulneración de derechos iusfundamentales inherentes a todo ser humano, entre otros, que no deberían ser limitados ante la inmunidad diplomática y requieren imperativamente que esta detente límites definidos, como toda figura jurídica.

En suma, la aplicabilidad de la inmunidad diplomática no puede interpretarse en el vacío, o in a vacuum (Tribunal Europeo de Derechos Humanos, 2010). Las características y circunstancias específicas de cada caso, la naturaleza de las cuestiones y la evolución del DI son factores que se deben tener plenamente en cuenta para lograr un equilibrio entre estos (Asamblea General de las Naciones Unidas, 1970) con el fin de aplicar de forma idónea esta figura conforme a las necesidades y exigencias actuales de la comunidad internacional, que no puede permitirse desatender aspectos vitales como el DIDH, DIH o normas del ius cogens, las cuales deben prevalecer per se ante la inmunidad diplomática.

A nivel regional, dentro del Sistema Interamericano de Protección y Promoción de los Derechos Humanos no existe jurisprudencia o regulación referente a la limitación en el ejercicio de la inmunidad diplomática, a pesar de que el Comité Jurídico Interamericano realizó en 1983 la base para una convención interamericana sobre la materia, que nunca llegó a plasmarse (OEA, 1983). Por ende, a nivel latinoamericano, nuestro faro es la Convención de la ONU, la cual ha sido la reglamentación con mayor ahínco respecto a las limitaciones de la inmunidad diplomática a nivel mundial.

Al respecto, la Convención de la ONU ha sido considerada una manifestación del DI consuetudinario en vigor (Tribunal Europeo de Derechos Humanos, 2016), siendo vinculante inclusive para Estados que no la hubiesen ratificado (Tribunal Europeo de Derechos Humanos, 2013). Sus límites a la inmunidad diplomática, consagrados en su título de la parte III, han sido aceptados de forma progresiva, al punto de 
considerárseles arraigados en la práctica estatal contemporánea, apoyando la inmunidad diplomática iure gestionis.

A pesar de lo anterior, los limites consagrados en la Convención de la ONU han sido interpretados de forma taxativa, lo cual, aunado al dinamismo del derecho y la multiplicidad de posibles sucesos facticos por acaecer, les tornan ineficientes e incompletos, por lo que, si bien referida convención significó un avance al respecto -podría decirse que es el único avance regulatorio hasta el momento-, posee limitantes que permiten la vulneración impune de derechos humanos y normas del ius cogens por personas con inmunidad diplomática, como acaece en el caso de los ilícitos cometidos por miembros de fuerzas armadas extranjeras en el país receptor, cuando estas gozan de inmunidad diplomática (Corte Internacional de Justicia, 2012).

Ahora bien, si el Estado acreditante se rehúsa a colaborar con el proceso judicial, en caso de solicitársele, es posible romper relaciones estatales o declarar persona non grata a los agentes que realicen actividades ilícitas, conforme al DI (Corte Internacional de Justicia, 1980). Esta declaración no debe ser motivada, pues aunque es una vía para proteger los Derechos de los nacionales del Estado receptor, constituye la última ratio para cualquier Estado, y no es dable ofrecerla como solución ante colisión de derechos humanos o normas del ius cogens frente a la inmunidad diplomática ya que los objetivos aludidos con esta figura, como se señaló previamente, son disímiles.

\subsection{Inmunidad iure imperii e iure gestionis}

Para entender la institución de la inmunidad diplomática debemos aludir que, si bien existió desde la antigua Grecia, después de la primera guerra mundial inició su transformación transversal como hoy la conocemos, al dividirla en inmunidad iure imperii (inmunidad absoluta) e iure gestionis (inmunidad restringida) (Casella, 2013). De esta forma, se distingue entre las actuaciones que corresponden al ejercicio de las prerrogativas del poder público del Estado y las actuaciones realizadas en condición similar a los particulares. Las primeras gozan de inmunidad de jurisdicción amplia, las segundas representan excepciones taxativas a dichas normas, aunque los tribunales del Estado del foro tienen jurisdicción y la pueden ejercer (Quintana Aranguren y Guzmán Carrasco, 2006)

La inmunidad iure gestionis versa que los tribunales del Estado de foro mantienen su competencia para juzgar los hechos en los que el Estado extranjero actúa como particular (Cruz Tejada, 2011). En otros términos, esta dimensión cobija exclusivamente los actos en ejercicio de sus funciones oficiales. Por otro lado, la inmunidad iure imperii ampara la integralidad de actos realizados por el Estado o sus representantes (Diez de Velasco, 2013). Es más, por regla general, los Estados gozan de inmunidad en los casos iure imperii (Abello-Galvis y Ferrer Acuña, 2013). 
Esta división no debe interpretarse de manera totalmente semejante a la inmunidad ratione personae y ratione materiae (Ambos, 2005), dado que, si bien son semejantes la primera con la inmunidad iure imperii y la última con la inmunidad iure gestionis, acto realizado a título privado no equivale necesariamente a los acta iure gestionis, como tampoco un acto realizado a título oficial es equiparable per se a los acta iure imperii (CDI, 2015), punto donde nacen complejidades prácticas y teóricas que solo podrían ser abordadas en un estudio aparte.

En este punto, es vital recordar la labor realizada por la Comisión de Derecho Internacional para definir los conceptos reseñados, la cual clasificó la inmunidad ratione personae como la que se predica de ciertos funcionarios del Estado, en virtud del relevante estatus que los mismos detentan en el Estado del que son nacionales y que les otorga de modo directo y automático una función de representación del mismo en el ámbito de las relaciones internacionales (CDI, 2013). Por otro lado, entiende la inmunidad ratione materiae como la que se predica de un funcionario del Estado en relación con los actos que este realiza en cumplimiento de su mandato y que pueden ser calificados como "actos oficiales" (CDI, 2013).

\subsection{Inmunidad de jurisdicción y ejecución}

La inmunidad diplomática se bifurca entre inmunidad de jurisdicción y ejecución. La primera tiene que ver con el derecho reconocido al agente diplomático de no ser sometido a la potestad judicial de otro Estado (Maklouf, 1990). La segunda se plantea cuando el sistema judicial, a pesar de poder ejercer jurisdicción en el caso concreto, le reconoce al agente el derecho de oponerse a ciertos actos de ejecución en determinados bienes ubicados en el Estado acreditante (Ozanam, 1910). Estas figuras resultan ligadas íntimamente y dificultan su distinción, aunque es imprescindible, puesto que con la primera no es posible iniciar un proceso judicial en contra de la persona que posee inmunidad, mientras que con la última se puede iniciar proceso judicial en el Estado receptor, con determinadas limitantes.

Al interior del TEDH, esta distinción se torna confusa (Tribunal Europeo de Derechos Humanos, 2009), dado que subsume la inmunidad de ejecución dentro del ámbito de la inmunidad de jurisdicción (Tribunal Europeo de Derechos Humanos, 2005), afectando la seguridad jurídica de todo aquel que pretenda ejercer recurso judicial contra persona con inmunidad diplomática.

Lo anterior puede ser provocado porque la inmunidad de jurisdicción siempre acompaña a la de ejecución, como señala el artículo 31.3 de la Convención de Viena. No obstante, se deben distinguir con claridad, pues la primera impide todo tipo de actuación judicial y la última posee un campo de acción más restringido.

Para finalizar este acápite, se aclara al lector que al hacer mención a la inmunidad diplomática nos referimos a la inmunidad de jurisdicción iure imperii donde se 
encuentran diversas omisiones y falencias a nivel internacional y nacional. Por otro lado, se omite la inmunidad de ejecución porque posee cualidades y características propias que obligarían a un estudio exclusivo de esta, y sobre la inmunidad iure gestionis porque el panorama nacional e internacional es satisfactorio.

\section{NORMAS DE IUS COGENS}

El presente apartado realiza un estudio base en relación al ius cogens. La complejidad y amplitud que entraña el tema solo podría ser profundizado de adecuada manera en un estudio individual, pues esta figura ha tenido un desarrollo histórico (Gómez Robledo, 1982) que actualmente ostenta su mayor fundamento convencional en los artículos 53 y 64 de la Convención de Viena de 1969, aunado a la importante contribución a su aceptación y desarrollo que se ha realizado a través de la Comisión de Derecho Internacional (CDI, 2014).

Son diversas las connotaciones y divergencias que suscita este tema, pues no se ha logrado ni a nivel nacional ni internacional una concepción uniforme en relación con lo que debiere entenderse por normas integrantes del ius cogens (Giardino Mardini, 2007). Si bien el artículo 53 lo consagró, no delimitó su contenido en ninguna dimensión (Abello-Galvis, 2011) y es solo a partir de la Convención de Viena que se desarrollan los elementos básicos de la naturaleza, requisitos y consecuencias del ius cogens (CDI, 2014).

Sin embargo, esto no es resultado del azar o falta de previsión en la Convención de Viena. El ius cogens no responde a una cláusula restringida y exclusiva, sino a la existencia de normas abiertas y materiales que no deben su obligatoriedad al derecho de los tratados, sino que responden a los intereses esenciales protegidos por la comunidad internacional (Cebada Romero, 2002), que al ser dinámicos deben estar abiertos al desarrollo social (Cepeda Rodríguez, 2016).

El ius cogens se materializa, entonces, como la representación de intereses mayores emanados desde la comunidad internacional, vinculantes para los Estados y que no pueden ser desconocidos bajo ningún precepto. Todo lo contrario, deben protegerse aun en las circunstancias más difíciles (Corte IDH, 2004). Justamente es en este punto donde el juez internacional debe aplicar su discrecionalidad para concretar el contenido, ya que los efectos y límites precisos del ius cogens siguen siendo objeto de controversia (CDI, 2014), aspecto que no sucede con su categoría y preminencia internacional.

\subsection{Inmunidad diplomática y normas del ius cogens}

La inmunidad diplomática y las normas del ius cogens son figuras coexistentes dentro del DI contemporáneo. Sin embargo, debe remarcarse la prevalencia internacional que poseen a priori estas últimas sobre todas las normas del DI que no cuenten con la misma calidad, siendo prerrogativas de carácter sustantivo y obligatorio cumplimien- 
to que guían el actuar de la comunidad internacional. Sin embargo, se ha iniciado el debate respecto a su aplicación, cuando quien las vulnera actúa bajo el amparo de la inmunidad diplomática, lo cual motiva el presente acápite.

Es importante resaltar la jurisprudencia del Tribunal Penal Internacional para la antigua Yugoslavia, que ha afirmado en los casos Blaskic (Tribunal Penal Internacional para la exYugoslavia, 1997), Furundzija (Tribunal Penal Internacional para la exYugoslavia, 1998), Karadzic (Tribunal Penal Internacional para la exYugoslavia, 1995) y Milosevic (Tribunal Penal Internacional para la exYugoslavia, 2001), la inaplicación de todo tipo de inmunidad en relación con los crímenes internacionales en prevalencia de normas de ius cogens, con independencia de que las actuaciones se desarrollen ante tribunales internacionales penales o nacionales extranjeros. De esta manera, se rescata la preminencia evidente que poseen las normas del ius cogens, especialmente en casos de crímenes de lesa humanidad.

La Corte Penal Internacional comparte posición con el Tribunal Penal Internacional para la exYugoslavia al considerar que cada uno de los Estados parte del Estatuto de la Corte Penal Internacional ha renunciado de manera expresa a toda inmunidad personal y funcional que sus agentes pudieran haber tenido frente a su tribunal conforme al DI consuetudinario. Así, da prevalencia a las normas imperativas de Derecho Internacional (Corte Penal Internacional, 2011).

Desde antaño, La CIJ ha negado controversia alguna entre las figuras enunciadas, en virtud del carácter procesal que posee la inmunidad diplomática. Así, niega la existencia de controversias o conflictos frente a normas sustantivas, como las normas del ius cogens. Por ende, aquella está limitada a determinar si los tribunales de un Estado pueden ejercer su competencia respecto de otro, por lo que no es relevante el análisis subjetivo referente al actuar del agente diplomático (Corte Internacional de Justicia, 2012).

Este argumento carece de fundamento, en tanto se deben respetar los derechos fundamentales de todo ser humano y no se puede subsumir su prevalencia a normas de carácter procesal, como la inmunidad diplomática (Corte Internacional de Justicia, 2012). Ello sería permitir la preponderancia de las buenas relaciones internacionales entre los Estados sobre los derechos humanos de quien no goce de inmunidad diplomática. De esto se infiere que quienes ostentan esta calidad gozan de mayor valía frente al Estado receptor, en perjuicio de la igualdad profesada en el DIDH.

Debido al argumento anterior, al interior de la CIJ se han manejado diferentes tesis, representadas en votos disidentes dentro de decisiones relacionadas, como la expresada por el exmagistrado Platón Morozov, referente a que cuando un Estado 
acreditante le genera perjuicios y/o daños al Estado receptor pierde el derecho a invocar la inmunidad diplomática en la respectiva relación (Corte Internacional de Justicia, 2012). En este sentido, se permite restringir la aplicación de la inmunidad diplomática a cuando se hubiese actuado conforme a derecho, especialmente el principio de la buena fe o la manifestada por el magistrado Cançado Trindade (Corte Internacional de Justicia, 2012) relativa a la protección erga omnes de los derechos humanos. Sin embargo, la posición mayoritaria actual de la CIJ es la no disensión entre la inmunidad diplomática y las normas del ius cogens, con lo que pregona implícitamente la prevalencia de aquella sobre las últimas, en perjuicio del DIDH.

En este sentido, nos alejamos de la teoría mayoritaria de la CIJ y se admite el carácter diferenciado de ambas figuras, si bien ello no puede impedir la aplicación erga omnes implícita en las normas del ius cogens, que no puede ser menoscabada bajo ninguna situación y menos por un aspecto meramente formalista (Corte Internacional de Justicia, 2012). En esta línea, expresar conformidad con la tesis de la CIJ sería aceptar conductas que fosilicen el DI y perjudicar un desarrollo progresivo del derecho.

El exmagistrado Cançado Trindade reitera la protección y especial prevalencia que poseen las normas del ius cogens, en mayor medida, cuando versa sobre la protección de los derechos humanos. En este sentido expresa:

Es erróneo suponer que no hay o no puede haber conflicto entre las "normas de Ius Cogens" sustantivas ... y las normas procesales de la inmunidad del Estado. ... El lus Cogens está por encima de la prerrogativa o el privilegio de la inmunidad del Estado, con todas las consecuencias que de ello se deriven, evitando así la denegación de justicia y la impunidad. (Corte Internacional de Justicia, 2012)

A raíz de las diferentes tesis al respecto y la extensión del texto, no es posible argumentar avenencia con algún sustento en específico, aunado a los diferentes alegatos que se suscitan a nivel internacional que resaltan que la tesis mayoritaria dentro de la CIJ ha sido la prevalencia de la inmunidad diplomática sobre las normas del ius cogens. Sin embargo, es imperioso remarcar la necesidad de modificar esta corriente, puesto que la prevalencia de las normas del ius cogens y el DIDH debe ser erga omnes (Abello-Galvis, CDI, 2011) y no puede ser aminorada por figuras como la inmunidad diplomática, que si bien son de significativa importancia, no deben anteponerse a aquellos por las razones expuestas.

Se debe traer a la memoria que las violaciones al ius cogens pueden acarrear consecuencias más allá del Estado infractor, porque todos los Estados tienen el derecho/ deber de invocar/exigir la responsabilidad erga omnes por violación de tales obligaciones (Estupiñán-Silva, 2011). Por ende, todos los Estados deben velar por su efectividad, inclusive en casos de personas que ostenten inmunidad diplomática. 
Se plantea la superioridad jerárquica de las normas de ius cogens, en tanto se ubican en la pirámide normativa en el DI. Por ende, si se da un conflicto entre la prohibición de cometer crímenes internacionales considerada de ius cogens y las normas consuetudinarias sobre inmunidades, consideradas estas últimas normas ordinarias, prevalecerán las primeras sobre las últimas, dado que la regulación sobre inmunidades diplomáticas no alcanza el estatus de ius cogens, pues esta no es reconocida como tal por la comunidad de Estados y debe ceder ante un concepto que refleja los más importantes valores que son compartidos por toda la comunidad internacional (Carrillo Santarelli, 2008).

Ahora bien, no es viable alegar una confusión en esta interpretación por la diferencia de categoría entre ambos cuerpos normativos. Se decantó que la inmunidad diplomática es de carácter adjetivo y las normas del ius cogens de carácter sustantivo, pues es clara la preminencia y especial relevancia dentro de la comunidad internacional que estas no pueden ser desatendidas por un aspecto formalista como el citado. Esta opinión la comparten diferentes doctrinantes (Giardino Mardini, 2007), pues vulneraría de manera directa el objetivo último de estas.

Sin embargo, las vulneraciones a las normas del ius cogens han sido reiteradas en diferentes niveles. El DIDH es el ámbito más perjudicado, específicamente el derecho de acceso a la justicia, como se evidencia en la jurisprudencia del TEDH y CIJ, pues a la presunta víctima le queda vedado acudir a la administración de justicia, razón por lo cual se estudia el caso en concreto del señalado derecho.

\subsubsection{Inmunidad y acceso a la justicia}

A través del tiempo han sido diversos los derechos humanos vulnerados por personas con inmunidad diplomática, como la vida, dignidad humana, igualdad, acceso a la justica. En este artículo solo se realizará una reflexión sobre el acceso a la justicia, no sin antes manifestar que ningún derecho humano puede ser considerado de jurisdicción doméstica, ya que su protección deriva del ius cogens (Corte Internacional de Justica, 1966). Esto quiere decir que debe cumplirse por la comunidad internacional en su conjunto (Cabra, 2011), de modo que resulta incomprensible la posición tomada por la CIJ señalada con antelación.

El acceso a la justicia debe asegurar, en tiempo razonable, el derecho de las presuntas víctimas o sus familiares a que se haga todo lo necesario para conocer la verdad de lo sucedido e investigar, juzgar y, en su caso, sancionar a los eventuales responsables (Corte IDH, 2017). Se debe proporcionar un recurso idóneo y eficaz, aun cuando los responsables gocen de inmunidad diplomática y recordar que no puede interpretarse como impunidad, pues no fue concebida para exceptuar la competencia sobre crímenes internacionales y violaciones al DIDH. 
Respecto a la aplicación de la inmunidad diplomática y el acceso a la justicia, el TEDH ha limitado el acceso a la justicia en diferentes ocasiones. Con ello manifiesta que no se considera vulnerado si se establecen restricciones que cumplan las normas del DI (Tribunal Europeo de Derechos Humanos, 2001), en aras de promover las buenas relaciones entre los Estados. Al respetar la soberanía estatal y atender a que el derecho de acceso a la justicia no es absoluto, admite restricciones proporcionales entre el fin legítimo y los medios para lograrlo (Tribunal Europeo de Derechos Humanos, 2014). Con todo, su restricción es desproporcional cuando desprotege de forma absoluta a la persona frente al actuar del personal diplomático, lo que ha causado diversidad de manifestaciones discordantes representadas en votos disidentes dentro de la misma corporación, como sucedió en la sentencia Al Adsani contra Reino Unido.

Se debe reiterar la discrepancia con decisiones similares a las precitadas, dado que este tipo de controversias deben resolverse a favor de la defensa y salvaguarda de los derechos humanos, en este caso el acceso a la justicia, con las prerrogativas legales correspondientes a cada parte dentro del proceso, especialmente en casos de crímenes internacionales. Esto permite el acceso a la administración de justicia a las presuntas víctimas, pues constituiría una vulneración a la evolución y dinamismo de los derechos humanos, junto con su literatura, desarrollo fáctico e intelectual, emprendido desde la modernidad.

En caso contrario, con la amplitud de exenciones y prerrogativas que emanan de aplicar la inmunidad diplomática iure imperii, nos remitiríamos nuevamente a la época clásica de la Grecia antigua, la cual se caracterizó por la cosificación del ser humano o su estratificación en clara contravía, per se, de la dignidad humana, por lo que debe restringirse conforme lo predica la literatura relacionada.

Conforme a lo anterior, es imperioso redefinir la resolución de controversias entre la aplicación de la inmunidad diplomática y el acceso a la justicia, debido a que se contrarían diferentes mandatos internacionales. Al interior de la CIJ y el TEDH han sido concurrentes los votos disidentes que están en desacuerdo con omitir el carácter dinámico y evolutivo del DI en relación con la interpretación y aplicación otorgada a la inmunidad diplomática. Así, previenen la inseguridad jurídica respecto a la prevalencia de los derechos humanos y normas del Ius Cogens, lo cual insta a reivindicar el derecho de estos, como del acceso a la justicia frente a la inmunidad y a entender que podría limitarse en determinados casos, de manera proporcional.

Para finalizar el presente acápite, es menester recordar la tesis del ex magistrado Cançado Trindade, relativa a la existencia de actos delicta imperii, que descarta la distinción acta iure gestionis y acta iure imperii, en caso de crímenes internacionales perpetrados por Estados, actos para los que no hay inmunidad (Corte Internacional 
de Justicia, 1980), por lo que propone una categoría de actos exentos de inmunidad, no desarrollada en debida forma por la comunidad internacional, que podría brindar luces respecto al problema jurídico planteado.

\section{INMUNIDAD DIPLOMÁTICA EN EL ORDENAMIENTO JURÍDICO COLOMBIANO}

Cada vez es más frecuente, ante los tribunales nacionales, el alegato según el cual "la inmunidad debe ser negada en caso de muerte o daños personales derivados de actos de un Estado en violación de las normas de derechos humanos dotadas de naturaleza ius cogens, particularmente la prohibición de la tortura" (CDI, 1999). Igualmente, la jurisprudencia de la CIJ ha enfatizado la importancia de los pronunciamientos realizados por los tribunales nacionales respecto a la inmunidad diplomática, pues, según la corporación, no se puede privilegiar la justeza de la responsabilidad alegada sobre la existencia de aquella (Lloret, 2017), bajo el entendido de la preminencia que goza la inmunidad dentro de citada corporación.

En Colombia, se ha diferido la regulación respecto a la inmunidad diplomática, a pesar de los reiterados casos en los cuales las personas que la poseían infringieron nuestro ordenamiento jurídico.

Como materialización de lo anterior, se presenta lo acontecido en diciembre de 2017 con el cónsul general de España en Colombia, quien estuvo involucrado en un accidente de tránsito en el que falleció un motociclista. Sobre este caso no se ha logrado esclarecer la totalidad de los hechos, en perjuicio de los derechos del difunto y su familia. En esta línea, a sabiendas de que al momento del acontecer el accidente no fue debido a sus funciones como cónsul, se refuerza la idea de la necesidad de una inmunidad iure gestionis, que permita la salvaguarda de derechos fundamentales, igualdad fáctica y debido funcionamiento del ordenamiento jurídico de todos los países.

En suma, dentro de nuestro ordenamiento jurídico, exceptuando las convenciones de Viena (1961) y de New York (1969) que fueron ratificados por Colombia, a nivel interno no se cuenta con una legislación que aborde íntegra y satisfactoriamente el tema, ni tampoco se ha ratificado convención o tratado que restringa la inmunidad diplomática, puesto que la Convención de la ONU no fue ratificada por nuestro Estado, por lo que solo contamos con la jurisprudencia de nuestras cortes de cierre que han pregonado diferentes posiciones a través del tiempo, mutan según cada órgano jurisdiccional y generan mayor inseguridad jurídica que la originada a nivel internacional. Parece que las decisiones a emitir dependen de la jurisdicción a la cual se acuda, en razón a que cada órgano de cierre posee su propia postura respecto a la aplicación de la inmunidad diplomática. 


\subsection{Desarrollo de la Corte Suprema de Justicia (CSJ)}

La Corte Suprema de Justicia ha sido la corporación nacional con mayor estudio respecto al tema que nos convoca. Inicia con la postura de la inmunidad absoluta desde 1987 (CSJ, 1987) hasta el año 2007 (CSJ, 2007) cuando su tesis mutó por la aplicación de la inmunidad restringida para que en el 2012 retomar su postura anterior (CSJ, 2012). Sin embargo, desde 2016 ha acudido a ambas figuras (CSJ, 2016), siendo la inmunidad absoluta su tesis predominante, pero con trazos de aplicación restringida en un grupo minoritario de providencias en los que se asienta la inseguridad jurídica y el vaivén al que se ven sometidos quienes deban someterse a su jurisdicción.

En el 2015, la CSJ, en aplicación de una inmunidad restringida (iure gestionis), declaró que, conforme al DI, los Estados tienen el deber de proteger los intereses de sus nacionales y residentes permanentes de carácter civil, comercial y con mayor razón cuando son trabajadores que reclaman salarios, prestaciones sociales, entre otros (CSJ, 2005). Por ende, las cortes colombianas tienen competencia para conocer determinadas controversias contra las misiones diplomáticas de Estados extranjeros, señalan que la inmunidad otorgada a las sedes extranjeras no puede ser absolutas ni pueden alegarse de manera irrestricta (CSJ, 2015).

Contrario sensu, en el año 2016 expresó que no es posible conocer los casos en contra de personas que gocen de inmunidad diplomática y que le corresponde al Estado reparar a la víctima por el daño antijurídico derivado de la desigualdad en las cargas públicas, pues las erogaciones emanadas de la inmunidad diplomática son imputables al actuar de nuestro Estado (CSJ, 2016). Ampara así la tesis de la inmunidad iure imperii y admite como únicas excepciones los casos de renuncia expresa a la inmunidad cuando el agente diplomático actúa como demandante y/o los litigios vinculados con derechos reales, aspectos sucesorales o controversias en desarrollo de actividades comerciales o profesionales, lo que excluye excepciones consagradas en la Convención de la ONU, que es parte del DI consuetudinario y debería ser aplicada conforme al bloque de constitucionalidad.

En 2017, retomando la tesis de 2015, expuso que aceptar la inmunidad diplomática de manera incondicional conllevaría a desconocer las atribuciones soberanas de Colombia para asegurar la defensa de derechos fundamentales (CSJ, 2017). De no hacerlo, nuestros nacionales estarían desprotegidos, incluso ante normas internacionales, lo que señala que las inmunidades jurisdiccionales otorgadas a las sedes extranjeras de otro país no pueden ser absolutas ni puede alegarse por estas de manera irrestricta. Así, transformaron su tesis por la inmunidad restringida.

De esta manera, se demuestra la poca claridad y uniformidad que presenta la CSJ, corporación que constantemente modifica su línea jurisprudencial al respecto. Si bien 
el derecho es dinámico, este tipo de tergiversaciones solo generan inseguridad jurídica y contravienen derechos fundamentales de los colombianos.

\subsection{Desarrollo del Consejo de Estado}

El Consejo de Estado posee una línea jurisprudencial con mayor uniformidad que la corporación estudiada previamente. A pesar de las modificaciones que ha sufrido la motivación de sus providencias, para esta corporación la responsabilidad y obligación de reparar recae en el Estado colombiano.

El 25 de agosto de 1998, por primera vez el Consejo de Estado (1998), siguiendo los fallos Caucheteux y Desmonts, admitió que el Estado, en cumplimiento legítimo de su función legislativa, podía ser agente generador de daños para los asociados. En este sentido, condenaron a la Nación por perjuicios causados a un colombiano por parte de un agente diplomático. Sustentaron que la Ley 6 (1972) impuso una carga desigual en cabeza de las víctimas de daños ocasionados por agentes diplomáticos, al restringir su derecho de acceso a la justicia y reparación, fallando la responsabilidad objetiva del Estado bajo el título de daño especial.

En este sentido, el legislador puede ser agente generador de daños para los asociados, dado que los privilegios concedidos a diplomáticos corren a cargo de la nación, que debe asumir las consecuencias derivadas del cumplimiento de sus obligaciones y relaciones diplomáticas (Consejo de Estado, 1998). La imposibilidad de reclamar el pago de ciertas indemnizaciones que le incumbiría pagar a los agentes diplomáticos implica un rompimiento de las cargas públicas, producto de las relaciones internacionales (Consejo de Estado, 2016), en perjuicio del acceso a la justicia.

El Consejo de Estado ha buscado un punto medio entre la defensa de los derechos y la aplicación de la inmunidad diplomática, en aras de no desconocer o desproteger ninguna de las dos instituciones. Cumple así una función loable. Sin embargo, ocasiona que la responsabilidad estatal llegue a puntos inconmensurables, por lo que se convierte en garante único y natural de todas las acciones u omisiones que realicen personas titulares de inmunidad diplomática en nuestro país (Quintana Aranguren y Guzmán Carrasco, 2006). Es un rol que el Estado no debe ni puede solventar.

A modo de excepción a lo antedicho, al dirimir acciones sobre controversias contractuales, el Consejo de Estado ha aplicado la inmunidad relativa, o iure gestionis. En relación con la simple celebración del negocio jurídico con un contratante amparado con dicha prerrogativa, sitúa a su cocontratante en un plano de desigualdad relativo porque se compromete la eficacia del principio pacta sunt servanda (Consejo de Estado, 2015). Reconoce, entonces, que la inmunidad absoluta restringe el derecho de acceso a la justicia, así como las facultades de jurisdicción del Estado. Sin embargo, la tesis predominante del Consejo de Estado, similar a la CSJ, es la aplicación de la inmunidad iure imperii, en perjuicio del DIDH. 


\subsection{Desarrollo de la Corte Constitucional}

La Corte Constitucional ha sido la corporación con posición más favorable a la prevalencia de los derechos humanos, normas del ius cogens y el bloque de constitucionalidad, puesto que ha defendido desde antaño la aplicación de la inmunidad restringida, iure gestionis (Sentencia T- 814, 2011). Se entiende que la inmunidad no es absoluta ni puede serlo, pues ningún Estado estaría en la capacidad jurídica de otorgar plena inmunidad diplomática respecto de cualquier actividad y sacrificar así las atribuciones que le competen como Estado libre y soberano para asegurar la defensa de los derechos de las personas sometidas a su jurisdicción (Sentencia C-137, 1996).

Advierte, entonces, que la inmunidad diplomática es una garantía que originalmente corresponde a una costumbre internacional reconocida como DI consuetudinario desde comienzos del siglo XIX. Es objeto de codificación y desarrollo progresivo en la Convención de Viena (1961), que surge del principio de igualdad de los Estados y se encamina a proteger su actuación soberana. Sin embargo, tiene límites que son dinámicos (Sentencia T-462, 2015) y han sido regulados por la convención de la ONU, por ser expresión del DI consuetudinario.

La inmunidad diplomática representa una excepción al principio de soberanía territorial del Estado receptor, lo cual motiva que sus salvedades no puedan interpretarse taxativamente. Tampoco excluyen la potestad estatal de establecer excepciones adicionales, en derecho interno o internacional (Sentencia T-462, 2015), lo que le permite al legislador regular el tema bajo estudio, con miras a generar seguridad jurídica. En este contexto, se han evidenciado diferencias entre las tesis de cada corte. Esto permite que la defensa de los derechos dependa de cada jurisdicción, lo cual exhorta a manejar una tesis uniforme, que permita defender el DIDH y normas del ius cogens sin desproteger intereses legítimos del Estado.

De esta forma, se debe seguir la línea delimitada por la Corte Constitucional con respecto a la aplicación restringida de la inmunidad diplomática, iure gestionis, en aras de la prevalencia y salvaguarda de los derechos humanos de todo ser humano que se torna indispensable para la aplicación de la inmunidad diplomática conforme a las prerrogativas del DIDH y las normas del ius cogens.

\section{CONCLUSIONES}

La prevalencia y valía de la inmunidad diplomática, a nivel de todas sus vertientes, ha transcendido a través del tiempo al punto que, desde la antigua Grecia hasta la actualidad, se ha planteado su aplicación sin ningún tipo de límites. Este hecho permite que se materialice de manera absoluta, más allá del ejercicio de las funciones de quien la posee, denominada iure imperii, lo cual ha motivado diferentes debates en la comunidad internacional, tanto a nivel doctrinario como jurisprudencial. Con respecto 
a este tema las opiniones son amplias y diversas con base en las consecuencias e implicaciones que suscita aplicar la inmunidad diplomática, sea iure imperii o iure gestionis, debido a la antigüedad y prevalencia que posee esta figura dentro del DI.

El anterior debate se da por la poca reglamentación respecto a los límites en la aplicación de la inmunidad diplomática, dado que las convenciones citadas, por su taxatividad y ausencia de desarrollo, no han brindado la seguridad jurídica suficiente frente a los retos que representa esta figura. Con mayor razón, cuando quienes actúan bajo su amparo contravienen el ordenamiento jurídico del Estado receptor. En estos casos estas vulneraciones permanecen impunes.

La situación se agudiza cuando quien actúa con inmunidad diplomática violenta normas del ius cogens, que son de imperativo cumplimiento, y la obligación de respetarlas y salvaguardas es erga omnes. En este aspecto es fundamental establecer una limitación al respecto porque cuando se trata de la prevalencia y salvaguarda del DIDH, que constituye uno de los más importantes avances de la humanidad desde la modernidad y que no puede verse menguado por la prevalencia de un aspecto formalista o procesal, debería dar paso a aspectos sustantivos, de fundamental relevancia para el statu quo internacional.

A la luz de la CIJ y el TEDH, la tesis prevalente en el caso de contravenciones entre la inmunidad diplomática y normas del ius cogens es la prevalencia de aquella. Así, se muta de tesis con respecto a cada caso concreto en perjuicio de las posibles víctimas de vulneración de derechos humanos, a quienes se le obstruye su acceso a la administración de justicia, no se brinda la posibilidad de esclarecer hechos relevantes y, en consecuencia, se les niega derechos como la vida, verdad, dignidad humana, igualdad, etc. Todo esto está en perjuicio de toda la gama de derechos humanos que se han fortalecido desde la Segunda Guerra Mundial.

En este contexto, es imperioso modificar la línea de los altos tribunales precitados, debido a que no es posible demostrar la aquiescencia con respecto a la vulneración impune de derechos humanos y mucho menos de normas del ius cogens, que a primera vista ostenta prevalencia a nivel internacional con respecto a todo tipo de normativa diferente. Esto ha motivado votos disidentes y debates al interior de las corporaciones antedichas que pregonan la prevalencia erga omnes de las normas del ius cogens y el DIDH según la costumbre internacional, puesto que, si bien ningún derecho es absoluto, sus límites deben ser proporcionados, equivalentes a fines y con medios justos.

Por otro lado, el desarrollo doctrinario ha sido exiguo. Si bien se han realizado estudios y reflexiones al respecto, la mayoría de las investigaciones científicas son de vieja data, mientas que las recientes son limitadas. Este es un campo que debe ser estudiado, analizado, aplicado y regulado con mayor rigurosidad, puesto que, como evidencia, la jurisprudencia a nivel nacional e internacional, los casos en que perso- 
nal con inmunidad diplomática efectúa violaciones a derechos humanos no es una cifra para desestimar.

Por lo pregonado en el presente trabajo, se concluye que la mejor opción, respecto a una regulación internacional (necesaria al respecto) o una postura de las cortes internacionales, sería la aplicación de la inmunidad iure gestionis. Claro está que la inmunidad diplomática nunca podrá ni deberá suprimirse, en virtud de su papel trascendental en el cumplimiento de las funciones estatales. Sin embargo, las exenciones y privilegios emanadas de la misma no pueden sobrepasar los límites mínimos que representan las normas del ius cogens y el DIDH, en tanto los últimos reproducen el fundamento base de toda la reglamentación y desarrollo del DI contemporáneo que debe ser respetado.

A nivel nacional, las controversias y debates respecto a la aplicación y límites de la inmunidad diplomática no han sido sosegadas ni unánimes, ya que existe un panorama aún más crítico. A nivel internacional, nuestras cortes de cierre manejan tesis totalmente divergentes, sin ningún tipo de similitud entre las mismas. En contraste, la Corte Suprema de Justicia modifica anualmente su posición al respecto, lo que genera inseguridad jurídica para quienes deben acudir a su jurisdicción, mientras que el Consejo de Estado deposita la totalidad de la responsabilidad al Estado colombiano en perjuicio del erario. En este sentido, ambas corporaciones aceptan la aplicación de la inmunidad diplomática iure imperii, en perjuicio de nuestra carta política y la integridad del bloque de constitucionalidad.

En otro orden de ideas, se debe resaltar la labor emprendida por la Corte Constitucional, debido a que es la única Corte de cierre a nivel interno con una tesis acorde a las necesidades nacionales e internacionales. Limita, así, conforme a la costumbre internacional, la aplicación de la inmunidad diplomática por el respeto de las normas del ius cogens y prerrogativas prestablecidas para su adecuada aplicación, que debe ser limitada conforme a derecho.

Por último, es importante reseñar la necesidad de regular legalmente, tanto a nivel nacional como internacional, los límites de la inmunidad diplomática, en razón a las controversias y disyuntivas que este suscita, como la prevalencia del DIDH, las normas del ius cogens, la seguridad jurídica, el acceso a la justicia, entre otros, que no pueden verse anulados por la inmunidad diplomática, como ha acaecido desde antaño en el contexto nacional e internacional (Asamblea General de las Naciones Unidas, 1970).

\section{REFERENCIAS}

Abello Galvis, R. (2011). Introducción al estudio de las normas de ius cogens en el seno de la comisión de derecho internacional, CDI. Vniversitas, 60(123), 75-104. https://revistas.javeriana.edu.co/index. php/vnijuri/article/view/14310 
Abello-Galvis, R. y Ferrer Acuña, C. (2014). Traducción del Fallo de la Corte Internacional de Justicia en el caso de las "Inmunidades Jurisdiccionales del Estado" (Alemania c. Italia; Grecia interviniente) Decisión sobre el Fondo . Anuario Colombiano de Derecho Internacional - ACDI , Vol.6 (2013) , 163-255. Universidad del Rosario.

Ambos, K. (2005). Inmunidades en derecho (penal) nacional e internacional. En J. Woischnik, Anuario de Derecho Constitucional Latinoamericano (pp. 691-718). Konrad-Adenauer-stiftung E.V.

Balzac, H. (1999). Maximes et pensées de Napoleón. De Fallois.

Cabra, M. G. (2011). Derecho Internacional Público. Temis.

Carrillo Santarelli, N. (2008). La inevitable supremacía del ius cogens frente a la inmunidad jurisdiccional de los Estados. Revista Jurídica Universidad Autónoma de Madrid,18, 55-82. https://revistas.uam.es/ revistajuridica/article/view/6067

Casella, D. A. (2013). La inmunidad soberana y el embargo de un buque de guerra: el caso A.R.A. Libertad. International Law. Revista Colombiana de Derecho Internacional, 17-53.

Cebada-Romero, A. (2002). Los conceptos de obligación erga omnes, ius cogens, y violación grave a la luz del nuevo proyecto de la CDI sobre Responsabilidad de los Estados por hechos ilícitos. Revista Electrónica de Estudios Internacionales, 4, 1-14. Obtenido de http://www.reei.org/index.php/ revista/num4/agora/conceptos-obligacion-erga-omnes-ius-cogens-violacion-grave-luz-nuevoproyecto-cdi-sobre-responsabilidad-estados-hechos-ilicitos

Cepeda-Rodríguez, E. (2016). Interrelación entre el ius cogens y el derecho blando. Derechos sociales y responsabilidad social corporativa en la justicia transicional. Revista de Derecho Público, 36, 1-26. http://dx.doi.org/10.15425/redepub.36.2016.02

Comisión de Derecho Internacional, CDI. (1980). Segundo Informe sobre las Inmunidades jurisdiccionales de los Estados y sus bienes. ONU.

Comisión de Derecho Internacional, CDI. (1999). Report of the working group on jurisdictional inmunities of state and their property. ONU.

Comisión de Derecho Internacional, CDI. (2013). Informe 65 periodo de sesiones. ONU.

Comisión de Derecho Internacional, CDI. (2014). Informe del 66 a período de sesiones. ONU.

Comisión de Derecho Internacional, CDI. (2015). Informe del 67 período de sesiones, A/70/10. ONU.

Committee on International Human Rights Law and Practice. (2000). Final Report on the Exercise of Universal Jurisdiction in Respect of Gross Human Rights offences: Conclusions and recommendations. London; ILA London Conference.

Congreso de la República de Colombia. (1972, 15 de noviembre). Ley 6 de 1972. Por la cual se aprueba la "Convención de Viena sobre Relaciones Diplomáticas hecha en Viena el 18 de abril de 1961". Diario oficial n. ${ }^{\circ} 33750$. http://bit.ly/2TMGQ2G

Consejo de Estado (1998, 25 de agosto). Sentencia No. IJ-001 (Vitelvina Rojas Robles M. P.) http:// bit.ly/2wBRWQ2

Consejo de Estado (2015, 4 de junio). Sentencia No. 33.776 (Olga Mélida Valle De La Hoz M. P.) http:// bit.ly/2wBRHEC 
Consejo de Estado. (2016, 09 de agosto). Sentencia 2002-01720-01 (Danilo Rojas Betancourth, M. P.) http://bit.ly/2PYVAdv

Corte Constitucional de Colombia. (1996, 9 de Abril). Sentencia C-137 (Eduardo Cifuentes Muñoz M. P.) http://bit.ly/3cFQixh

Corte Constitucional de Colombia. (2011, 12 de Abril). Sentencia T- 814 (Luis Ernesto Vargas Silva, M. P.) http://bit.ly/3clBNJ1

Corte Constitucional de Colombia (2015, 22 de Julio). Sentencia T-462 (Gloria Stella Ortiz Delgado, M. P.). http://bit.ly/3cDOK6z

Corte Interamericana de Derechos Humanos. (2004, 07 de septiembre). Sentencia Tibi vs. Ecuador. http://bit.ly/2vG6gXP

Corte Interamericana de Derechos Humanos. (2017, 25 de marzo). Sentencia Acosta y Otros vs Nicaragua. http://bit.ly/38xEZnB

Corte Internacional de Justicia. (1966, 18 de julio). Sentencia Etiopia vs. Sudáfrica. http://bit.ly/39vgAjQ

Corte Internacional de Justicia. (1980, 24 de mayo). Sentencia Estados Unidos de América vs. República Islámica de Irán. http://bit.ly/39A0jKr

Corte Internacional de Justicia. (2012, 3 de febrero). Sentencia Alemania c. Italia: Intervención de Grecia. http://bit.ly/2wEEqv7

Corte Internacional de Juticia. (2012, 3 de febrero). Sentencia Alemania c. Italia: Intervención de Grecia (Antonio Cançado Trindade, Voto discidente) http://bit.ly/2wEEqv7

Corte Internacional de Justicia. (2012, 3 de febrero) Sentencia Alemania c. Italia: Intervención de Grecia (Platón Morozov, Voto discidente) http://bit.ly/2wEEqv7

Corte Penal Internacional. (2011, 12 de diciembre). Fiscal Omar Hassan Ahmad Al Bashir. http://bit. ly/2IwmeXa

Corte Suprema de Justicia. (1987, 5 de junio). Sentencia 10009 (Jorge Ivan Palacio Palacio M. P.) http:// bit.ly/39A9c6U

Corte Suprema de Justicia. (2005, 13 de abril). Sentencia 25679 (Francisco Ricaurte Gómez, M. P.) http://bit.ly/38wmTm4

Corte Suprema de Justicia. (2007, 13 de diciembre). Auto 32096 (Camilo Tarquino Gallego, M. P.) http://bit.ly/2TOFRya

Corte Suprema de Justicia. (2012, 21 de marzo). Sentencia 37.637 (Luis Gabriel Miranda Buelvas, M.P.) http://bit.ly/2PXPTwG

Corte Suprema de Justicia. (2015, 27 de noviembre). Sentencia C 16431-2015 (Ariel Salazar Ramírez, M. P.) http://bit.ly/2PU2XD2

Corte Suprema de Justicia. (2016, 20 de abril). Auto AL2343-2016/72569 (Clara Dueñas Quevedo, M. P.). http://bit.ly/2W1KEQp

Corte Suprema de Justicia. (2016, 25 de octubre). Auto C7245-2016 (Aroldo Quiroz Monsalvo, M. P.). http://bit.ly/3aEzQM8 
Corte Suprema de Justicia. (2017, 24 de enero). Sentencia 460-2017/2016-03672 (Ariel Salazar Ramírez, M. P.). http://bit.ly/2Irewxo

Cruz-Tejada, H. (2011). Aproximación a la inmunidad de jurisdicción y de ejecución de los estados extranjeros ante tribunales colombianos. Revista del Instituto Colombiano de Derecho Procesal, 37(37). http://dx.doi.org/10.32853/01232479.v37.n37.2011.53

Diez de Velasco, M. (2013). Instituciones de Derecho Internaciona Público. Tecnos.

Dominicé, C. (1999). The International Responsibility of States for Breach of Multilateral Obligations. European Journal of International Law, 10(2), 353-363. http://www.ejil.org/pdfs/10/2/585.pdf

Estupiñán-Silva, R. (2011). La responsabilidad estatal por violaciones graves del DIDH y DIH en el sistema de las Naciones Unidas. Criterio Jurídico Garantista, 3(5), 88-111. http://bit.ly/2ItCPL9

Ferrer-Lloret, J., (2017). La inmunidad de jurisdicción del Estado ante el TEDH: La alargada sombre del Derecho Internacional Consuetudinario. Revista electrónica de estudios internacionales, 34, 1-56, http://bit.ly/38AQgnb

Giardino-Mardini, G. (2007). Inmunidades vs. Ius Cogens: ¿Existe realmente un conflicto entre ambos cuerpos? Agenda Internacional, 14(25), 89-103. http://bit.ly/2TP59go

Gómez-Robledo, A. (1982). El Ius Cogens Internacional (estudio histórico-crítico). Instituto de Investigación Jurídicas, Universidad Nacional Autónoma de México.

Honoré, B. (1999). Maximes et pensées de Napoleón. De Fallois.

Maklouf, A. (1990). Derecho Diplomatico, Derecho Consular y Normativa Costarricense. Litografía Cosmos.

Nuñez, L., y Cifuentes, G. (2016). Cambio de mentalidad frente a la inmunidad de jurisdicción. Revista virtual Via Inveniendi et Iudicandi, 11(2), 69-86. DOI: https://doi.org/10.15332/s1909-0528.2016.0002.03

Organización de las Naciones Unidas. (1970, 24 de Octubre de 1970). Declaración relativa a los principios de Derechos Internacional referentes a las relaciones de amistad y a la cooperación entre los Estados de conformidad con la Carta de las naciones unidas. Resolución 2625. Nueva York, Estados Unidos. http://bit.ly/2TC7VXz

Organización de las Naciones Unidas. (1969, 16 de diciembre). Convención sobre las misiones especiales. Conferencia de las Naciones Unidas sobre Relaciones e Inmunidades Diplomáticas. Nueva York, Estados Unidos. http://bit.ly/2TPBAen

Organización de las Naciones Unidas. (1969, 18 de abril). Convención de Viena sobre Relaciones Diplomáticas. Conferencia de las Naciones Unidas sobre Relaciones e Inmunidades Diplomaticas. ONU. http:// bit.ly/38xulxk

Organización de las Naciones Unidas. (2004, 16 de Diciembre ). Convención de las Naciones Unidas sobre las inmunidades jurisdiccionales de los Estados y de sus bienes. Resolución 59/38. New York, Estados Unidos. http://bit.ly/3aBtFIp

Organización de los Estados Americanos. (1983, 4 de Febrero). Proyecto de convención interamericana sobre inmunidad de jurisdicción de los Estados.

Ozanam, C. (1910). L'immunite civile de juridiction des agents diplomatiquees. Pedone.

Quintana-Aranguren, J. y Guzmán-Carrasco, G. (2006). De Espaldas al Derecho Internacional; Colombia y la Inmunidad de Jurisdicción de los Estados. International Law. Revista Colombiana de Derecho Internacional, 4(8), 53-102. http://bit.ly/2vENoZf 
Tribunal Europeo de Derechos Humanos. (2001, 21 de noviembre). Sentencia McElhinney vs. Ireland. http://bit.ly/38DMyta

Tribunal Europeo de Derechos Humanos. (2005, 3 de Marzo). Sentencia Manoilescu and Dobrescu vs. Romania and Russia. http://bit.ly/38tUzRjhttp://bit.ly/2TuRPPg

Tribunal Europeo de Derechos Humanos. (2013, 20 de junio). Sentencia Wallishauser v. Austria. http://bit.ly/2TFXXms

Tribunal Europeo de Derechos Humanos. (2014, 14 de enero). Sentencia Jones and Others v. Reino Unido. http://bit.ly/2wzdnkJ

Tribunal Europeo de Derechos Humanos. (2016, 25 de octubre). Sentencia Radunovic and Other v. Montenegro. http://bit.ly/3azpPj9

Tribunal Penal Internacional para la exYugoslavia. (1995, 16 de mayo). Sentencia Fiscal vs. Karadzić http://bit.ly/2THxlle .

Tribunal Penal Internacional para la exYugoslavia. (1997, 29 de octubre). Sentencia Fiscal vs. Blaškić. http://bit.ly/2v2FMiG

Tribunal Penal Internacional para la exYugoslavia. (1998, 10 de diciembre). Sentencia Fiscal vs. Furundzija. http://bit.ly/2TAUmaR

Tribunal Penal Internacional para la exYugoslavia. (2001, 8 de noviembre). Sentencia Fiscal vs. Milosevic Slobodan. http://bit.ly/3cBHust

United States Supreme Court. (1812, 24 de febrero). Sentencia The schooner "Exchange" c. Mc Faddon and others. http://bit.ly/330lXoF

Verdross, A. (1955). Derecho Internacional Público. Biblioteca Jurídica Aguilar.

Yang, X. (2013). State immunity in International Law. Cambridge University Press.

Zomosa-Signoret, A. (2002). Derecho Internacional y política exterior: una aproximación a la realidad. Políticia y Cultura, 18, 179-193. http://bit.ly/3aElZFA 